\title{
NON-LOCALISED NEGATIVE INTERFERENCE IN ASPERGILLUS NIDULANS
}

\author{
CHARLES G. ELLIOTT * \\ Department of Genetics, University of Glasgow
}

\section{INTRODUCTION}

Received 6.v.6o

WHEN the incidence of recombination in regions adjacent to a very short segment of a chromosome (i.e. one less than $\mathrm{I}$ unit in length) is measured $(a)$ in a whole population of meiotic products and $(b)$ in that small proportion of the population in which there has been recombination between the marker genes delimiting the short segment, it is found that the values for $(b)$ are higher than for $(a)$ : there is negative interference between exchanges in the short segment and the adjacent regions (Pritchard, 1955; 1960; Calef, 1957, in Aspergillus nidulans; Streisinger and Franklin, 1956, in phage $\mathrm{T}_{2}$, and Chase and Doermann, I958, in phage $\mathrm{T}_{4}$ ).

In practice, the two sets of recombination fractions, for $(a)$ and (b), are estimated in two different samples from the population. of meiotic products. One, called in the present paper the unselected sample, is a random sample of the whole population. The other, called the selected sample, consists only of recombinants between the closely linked markers. The short segment, the rare recombinants in which comprise the selected sample, will be called the selective region.

The unselected sample is obtained, in Aspergillus nidulans, by plating a suspension of ascospores, representing the population of meiotic products, on a non-selective medium on which all can grow. The selected sample is obtained by plating ascospores from the same suspension on a selective medium on which only the rare recombinants will grow. In a selective plating of this kind, only half the recombinants are recovered; e.g. in the cross $a+/ /+b$, in which $a$ and $b$ are mutant alleles determining growth factor requirements, only the prototrophic ++ recombinants grow and the double auxotrophs $a b$ do not. The technique has the disadvantage that those prototrophic colonies which may result from processes other than recombination, e.g. mutation, cannot be distinguished from recombinants, but the intensity of negative interference would in this case be underestimated.

"Selection", used as an opposite to random sampling of products of meiosis, must not be confused with its use in, say, breeding experiments, where it refers to the choice of the parents of a further generation.

Negative interference between exchanges in two regions, or in other words a positive correlation between them, means that crossingover in these regions is not independent, more cells than expected

* Present address : Botany Department, University of Glasgow. 
having exchanges in both. The distribution of crossing-over between the regions is non-random. Negative interference can arise from pooling two populations of meiotic products in which the incidence of crossing-over is higher in both regions in one population than in the other (Sturtevant, I955). The two populations could be, for example, the products of different sexes (cf. Drosophila as an extreme case), or of different individuals of the same sex, or even of one individual if there were for example systematic variation in the incidence of recombination with age. Crossing-over may be distributed non-randomly over the whole chromosome set, or only in a single chromosome; over a long segment of a chromosome or only within a very short segment.

It has been suggested that the high intensity of negative interference between exchanges in a very short region of a chromosome, less than one unit in length, and the adjacent regions is due to a non-random distribution of crossing-over within short segments; in other words, to a localised clustering of exchanges (Pritchard, 1955, I960; Chase and Doermann, I958). Pritchard supposes that "effective pairing ", the condition necessary for exchanges to occur, is confined to short segments in which more than one exchange can occur; in the segment between two effectively paired segments there is no effective pairing and no crossing-over. The whole population includes the products of many cells which were effectively unpaired in the selective region; the selected sample consists only of the products of cells with effective pairing within the short region. The extension of pairing to one, the other or both sides of the selective region will increase the incidence of recombination in these adjacent regions, but not in other regions, in the selected as compared with the unselected sample.

On the other hand, if crossing-over is distributed non-randomly throughout the nucleus, so that no exchange is independent of any other, the incidence of recombination will be higher in a selected sample of cross-overs than in an unselected sample in all regions.

The present work is an attempt to decide whether negative interference in Aspergillus nidulans is purely localised, or whether there is also present a generalised effect, extending perhaps throughout the nucleus. Localised and generalised negative interference may be distinguished by comparing the difference between the recombination fractions in selected and unselected samples for the regions adjacent to a short selective region, for a further region on the same chromosome, and for one on a different chromosome.

In hyacinths, temperature determines whether there is a positive correlation or no correlation between the chiasma frequencies of different bivalents (Elliott, I958). Crosses in Aspergillus were therefore made at different temperatures. If crossing-over in different bivalents is positively correlated, we expect the recombination fractions in a chromosome other than that carrying the selective region to be higher 
than in the unselected sample. If there is no correlation between different bivalents, these recombination fractions should be the same. Generalised negative interference might thus be detectable at one temperature but not at another.

\section{2 (i). CROSS 1: pro1 ad17 y; Acr1 w3 x paba1 bi1}

\section{(a) Experimental details}

The linkage maps for these markers, together with the standard map lengths (at $37^{\circ}$ ) (Käfer, I958) are:

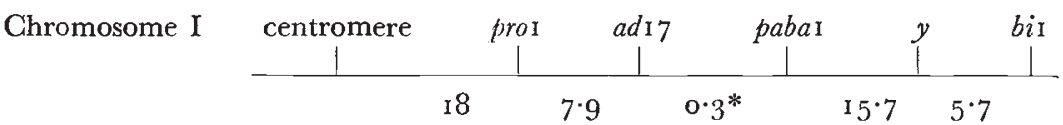

Chromosome II

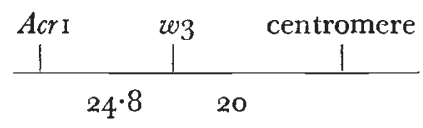

This cross was designed to have (i) a short region, ad-paba, less than I unit in length,* in which selection for rare cross-overs could be made (selective region), (ii) marked regions on either side of this short region (pro-ad, paba-y), (iii) a region on the same chromosome not adjacent to the short interval $(y-b i)$, (iv) a region in another chromosome (Acr-w).

The parental strains were inoculated together on minimal medium and placed at $25^{\circ}, 37^{\circ}$ and $42^{\circ}$ until perithecia were mature. A suspension of ascospores from a large number of perithecia was plated on (i) minimal medium supplemented with proline, adenine, $p$-aminobenzoic acid and biotin (non-selective), (ii) minimal medium with proline and biotin (selecting recombinants $a d^{+} p a b a^{+}$), and incubated at $37^{\circ}$ in all cases.

The data given for each temperature are the combined results of several platings. The different platings were tested for heterogeneity by comparing the numbers of cross-overs and non-cross-overs in each plating for each of the regions pro-ad, paba-y, y-bi and Acr-w. For the selective and non-selective platings at the three temperatures the value of $\chi^{2}$ exceeded its 5 per cent. level in one out of 23 cases, and although too many values exceeded the $5^{\circ}$ per cent. level, the data may be considered sufficiently homogeneous.

The recombination fractions observed are given in table $\mathrm{I}$. Those for the regions paba-y and $y-b i$ are based on only about half the products of meiosis, i.e. those carrying $w^{+}$, because the other half, carrying $w$, are colourless and therefore cannot be classified as $y$ or $y^{+}$.

Since the fungus is homothallic, the unselected samples must be examined to see whether there is any evidence of a high proportion

* In a total of 5724 unselected strands (pooled data of several crosses), I have found the distance between these markers to be $0.63 \pm 0.10$ units. This agrees with the value of 0.54 which results from the data of Calef's (1957) table 3, but which was incorrectly given by him as $0 \cdot 24$. 
of selfed asci. An excess of parental types in the population due to selfing would reduce the recombination fractions for all regions in the unselected sample, and accentuate any real differences between the selected sample (which consists of recombinants only) and the unselected sample; i.e. it would produce negative interference of the generalised type. Selfing would be judged significant if the number in the fully parental class (e.g. paba bi) was greater than that arising through recombination of chromosomes without crossing-over (paba bi

TABLE I

Results of cross $I$ :

$\frac{p r o \mathrm{I} a d \mathrm{I} 7+y+\frac{A c r \mathrm{I} w 3}{++p a b a \mathrm{I}+b i \mathrm{I}}}{++}$

\begin{tabular}{|c|c|c|c|c|c|c|c|c|c|}
\hline & \multicolumn{3}{|c|}{$25^{\circ}$} & \multicolumn{3}{|c|}{$37^{\circ}$} & \multicolumn{3}{|c|}{$4^{2^{\circ}}$} \\
\hline & $\mathcal{N}$ & $S$ & $R I$ & $\mathcal{N}$ & $S$ & $R I$ & $\mathcal{N}$ & $S$ & $R I$ \\
\hline $\begin{array}{l}\text { Chromosome I } \\
p r o \mathrm{I}-a d d_{\mathrm{I}} 7 \\
a d \mathrm{I}_{\mathrm{I}}-p a b a \mathrm{I} \\
p a b a \mathrm{I}-y \\
y-b i \mathrm{I}\end{array}$ & $\begin{array}{r}13 \cdot 48 \\
0 \cdot 98 \\
28 \cdot 21 \\
6 \cdot 01\end{array}$ & $\begin{array}{c}\text { I } 4 \cdot 42 \\
\text { selected } \\
32 \cdot 67 \\
9 \cdot 07\end{array}$ & $\begin{array}{l}7 \\
\cdots \\
16 \\
5 \mathrm{I}^{*}\end{array}$ & $\begin{array}{r}8 \cdot 76 \\
\mathrm{I} \cdot 70 \\
16 \cdot 53 \\
5 \cdot 46\end{array}$ & \begin{tabular}{|c} 
Io.8I \\
selected \\
$22 \cdot 47$ \\
$6 \cdot 26$
\end{tabular} & $\begin{array}{l}23 \\
\ldots \\
36^{*} \\
15\end{array}$ & $\begin{array}{l}4 \cdot 01 \\
0 \cdot 38 \\
6 \cdot 49 \\
\text { I.39 }\end{array}$ & $\begin{array}{c}9 \cdot 65 \\
\text { selected } \\
\text { I I } 66 \\
4 \cdot 95\end{array}$ & $\begin{array}{l}14^{*} \\
\dddot{68} \\
68^{*} \\
25^{*}\end{array}$ \\
\hline $\begin{array}{c}\text { Chromosome II } \\
\text { Acri }-w_{3} .\end{array}$ & $29 \cdot 02$ & $29 \cdot 65$ & 2 & $24 \cdot 5^{8}$ & $27 \cdot 6$ I & 12 & 17.27 & $2 I \cdot 3 I$ & 23 \\
\hline $\begin{array}{l}\text { No. of colonies } \\
\text { Total } \\
w^{+}\end{array}$ & $\begin{array}{r}\text { I I } 20 \\
599\end{array}$ & $\begin{array}{r}\text { I IO } 3 \\
55^{\mathrm{I}}\end{array}$ & & $\begin{array}{r}\text { I I I } 9 \\
623\end{array}$ & $\begin{array}{r}\text { I IO I } \\
543\end{array}$ & & $\begin{array}{l}799 \\
43^{2}\end{array}$ & $\begin{array}{l}549 \\
283\end{array}$ & \\
\hline
\end{tabular}

$\mathcal{N}=$ recombination fraction (per cent.) in unselected samples.

$S=$ recombination fraction (per cent.) in selected samples (recombinants selected : $\left.a d^{+} p a b a^{+}\right)$.

$R I=\frac{S-\mathcal{N}}{\mathcal{N}} \times$ Ioo.

The recombination fractions for $p a b a-y$ and $y-b i$ are based on the number of $w^{+}$ colonies, those for other regions on the total number.

* Difference between $S$ and $\mathcal{N}$ significant at 5 per cent. level.

Acrw) when compared with the classes in which there had been crossing-over in chromosome II; i.e.,

$$
\text { pababi }++ \text { : pababi Acrw :: pababi Acr }+ \text { : pababi }+w .
$$

Such data are given in table 2. It is evident that the proportions of the first two classes agree in all cases with those of the second two. The difference between the classes in each pair is due to the recovery of fewer white than non-white colonies. (Among the recombinants with combinations of nutritional markers other than pro ad and paba $b i$ there were also fewer $w$ than $w^{+}$colonies.) Furthermore, when parental classes were eliminated by selecting on paper recombinants between markers on different chromosomes, the recombination 
fractions calculated on half the data were changed by rather less than their standard errors, and at each temperature the recombination fractions for some regions among these "interchromosomal recombinants" were less and for other regions greater than those calculated on the total data. Hence in this cross the vast majority of asci must be of hybrid origin.

Some of the colonies growing on the selective media were diploids (Pritchard, I954); these have been excluded from the results. At

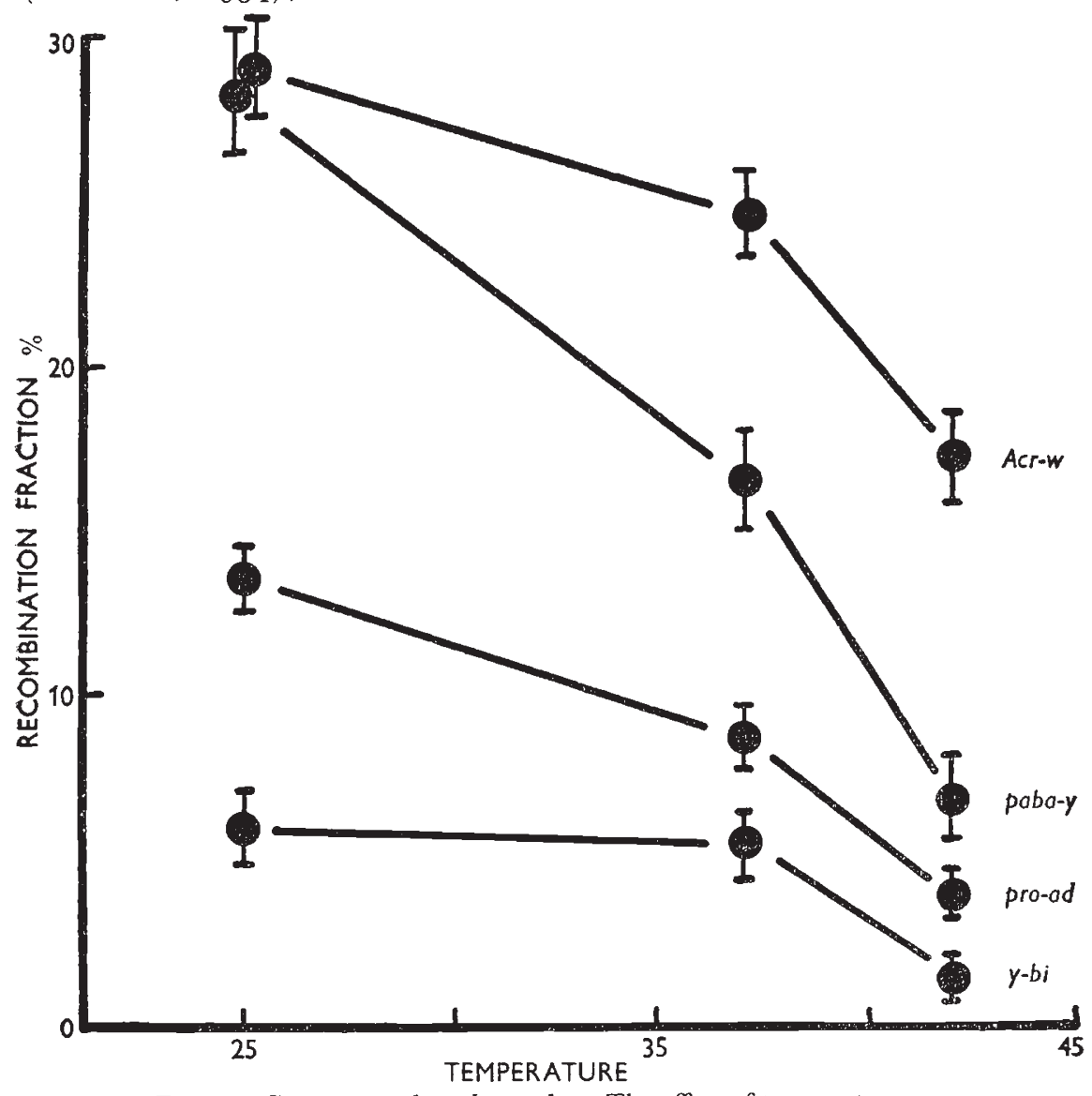

Fig. 1.-Cross I, unselected samples. The effect of temperature on recombination fractions for four regions.

$25^{\circ}$ and $37^{\circ}$ they comprised about I 3 per cent. of the colonies, but at $42^{\circ}$ they were much more numerous (over I4 per cent. of wellgrowing colonies), and there were besides many small or irregular and poorly growing colonies, believed to be aneuploids, which were not tested.

\section{(b) Results}

The effect of temperature in the unselected samples. For all regions, the highest recombination fractions are observed at $25^{\circ}$ and the lowest at $42^{\circ}$ (table I, fig. I). All differences between temperatures are 
significant, except for $y$-bi between $25^{\circ}$ and $37^{\circ}$. The frequency of strands with no exchange in the marked region of chromosome I

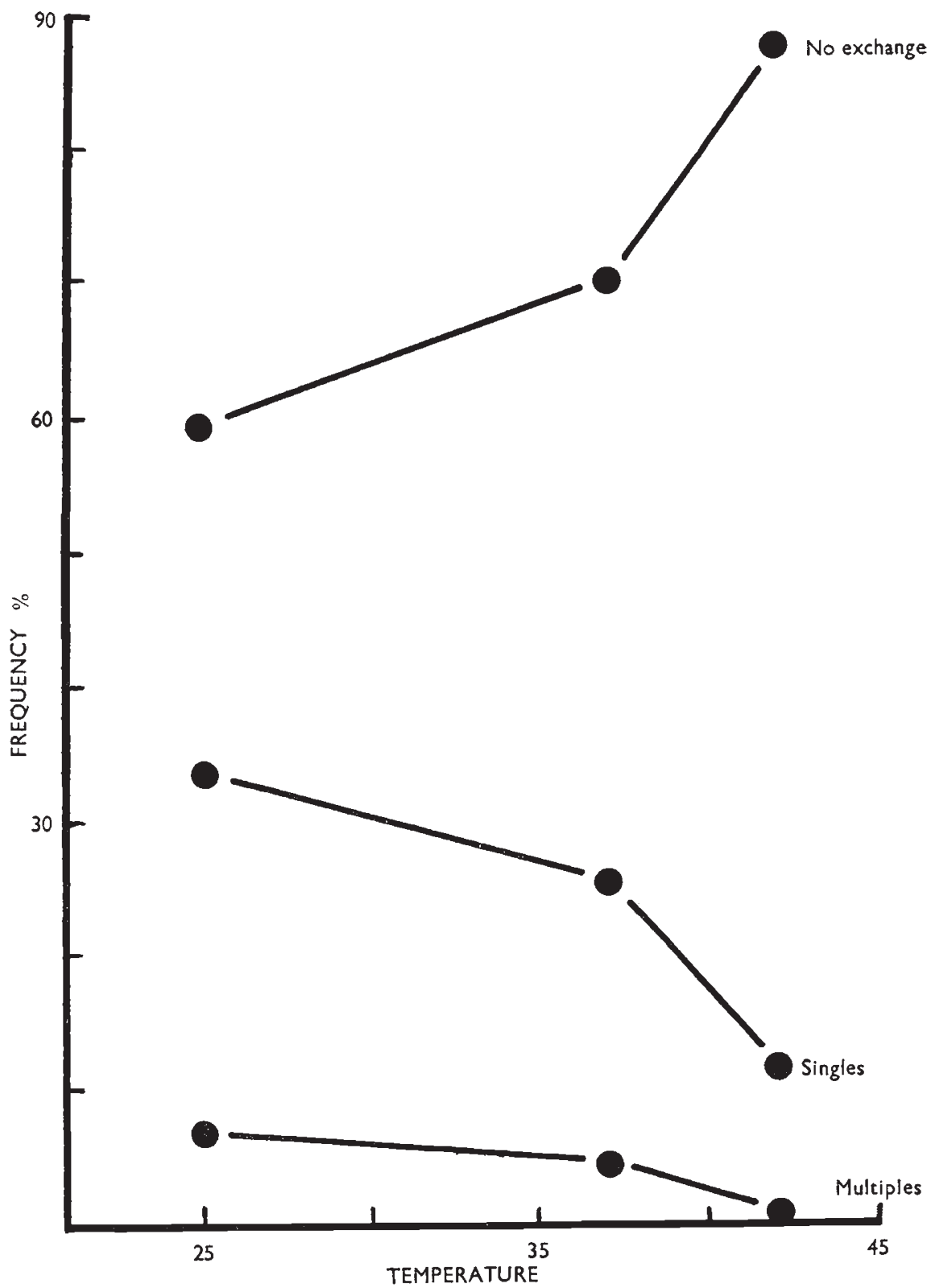

Fig. 2.-Cross I, unselected samples. The effect of temperature on the frequency of strands with no exchange, with one, and with more than one exchange in four regions of Chromosome I.

increases with increasing temperature, and the frequency of singles and multiples decreases (fig. 2).

Temperature not only affects the total amount of crossing-over, 
but alters its distribution among the four marked regions in chromosome I. The lengths of these regions relative to the total distance pro-bi at the three temperatures are shown in fig. 3. The relative length of the region pro-ad (i.e. the proportion of all exchanges which fall within that region) increases with increasing temperature, though not

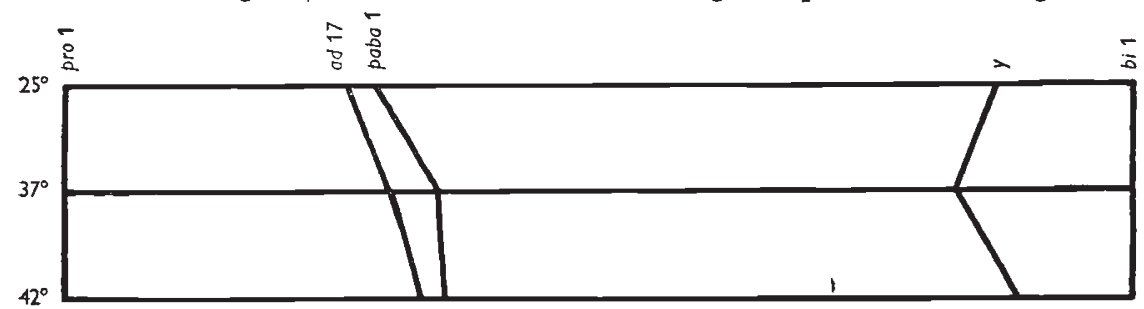

FIG. 3.-Cross I, unselected samples. The lengths of the various regions in Chromosome I relative to the total distance pro $\mathrm{I}-b i_{\mathrm{I}}$ at different temperatures.

significantly. The relative length of the region paba-y is, however, less at $37^{\circ}$ than at $25^{\circ}$ and $42^{\circ}$; the difference between $25^{\circ}$ and $37^{\circ}$ is significant, but not that between $37^{\circ}$ and $42^{\circ}$.

In contrast to the observations on Drosophila (Plough, I9I7, I92 I ; Stern, I926), a greater effect of temperature on the incidence of

TABLE 2

Cross I. Data comparing the numbers of Chromosome I non-cross-overs (pro ad y and paba bi) with and without recombination for the Chromosome II markers (Acr and w)

\begin{tabular}{|c|c|c|c|c|c|}
\hline Temperature & pro ad Acr w & pro ad ++ & proad $+w$ & pro ad Acr + & $\chi_{[1]}^{2}$ \\
\hline $\begin{array}{l}25 \\
37 \\
42\end{array}$ & $\begin{array}{r}97 \\
120 \\
106\end{array}$ & $\begin{array}{l}\text { I } 23^{*} \\
\text { I } 43 \$ \\
\text { I } 2\end{array}$ & $\begin{array}{l}44 \\
47 \\
21\end{array}$ & $\begin{array}{l}50^{\dagger} \\
5 I^{* *} \\
3^{1}\end{array}$ & $\begin{array}{l}0 \cdot 20 \\
O \cdot 16 \\
\mathrm{I} \cdot \mathrm{I} 4\end{array}$ \\
\hline & $p a b a b i++$ & paba bi Acr w & paba bi Acr + & $p a b a b i+w$ & \\
\hline $\begin{array}{l}25 \\
37 \\
42\end{array}$ & $\begin{array}{l}\text { 1 } 4^{8 \dagger \dagger} \\
191 \\
204\end{array}$ & $\begin{array}{l}\text { I } 17 \\
140 \\
\text { I6o }\end{array}$ & $\begin{array}{l}50 \S \S \\
59^{* * *} \\
33\end{array}$ & $\begin{array}{l}46 \\
36 \\
30\end{array}$ & $\begin{array}{l}0.42 \\
0.59 \\
0.29\end{array}$ \\
\hline
\end{tabular}

* includes one pro ad $y^{+}$

$\dagger$ includes one pro ad $y^{+}$Acr

$\S$ includes one pro ad $y^{+}$
** includes two pro ad $y^{+}$Acr

$\dagger \dagger$ includes seven paba y bi

$\S \S$ includes one paba y bi Acr

*** includes one paba y bi Acr

crossing-over is shown by the region paba-y than by one, namely pro-ad, which is closer to the centromere.

Recombination fractions in the samples of rare cross-overs. As seen in table $\mathrm{I}$, the recombination fractions in the selected samples (i.e. among the rare cross-overs in the short region $a d-p a b a)$ are greater than in the unselected samples for all regions. The magnitude of the increase in recombination fraction in the selected samples is best 
considered as relative to the length of the region in the unselected samples (RI in table I). The effect of temperature on the magnitude of the increase differs for the various regions, as follows:

(a) In the two regions pro-ad and paba-y, which are adjacent to the selective region, the smallest increases are observed at $25^{\circ}$ and the

TABLE 3

Recombination fractions (per cent.) for Acr-w in unselected and selected samples in the separate platings, with tests of significance of difference between samples

\begin{tabular}{|c|c|c|c|c|c|c|c|}
\hline \multirow{2}{*}{$\begin{array}{l}\text { Temper- } \\
\text { ature }\end{array}$} & \multirow{2}{*}{ Plating } & \multicolumn{2}{|c|}{ Unselected samples } & \multicolumn{2}{|c|}{ Selected samples } & \multirow{2}{*}{$\chi_{[1]}^{2}$} & \multirow{2}{*}{$\chi$} \\
\hline & & $\begin{array}{l}\text { Recombina- } \\
\text { tion fraction }\end{array}$ & $\begin{array}{l}\text { No. of } \\
\text { colonies }\end{array}$ & $\begin{array}{l}\text { Recombina- } \\
\text { tion fraction }\end{array}$ & $\begin{array}{l}\text { No. of } \\
\text { colonies }\end{array}$ & & \\
\hline \multicolumn{8}{|c|}{ Cross I } \\
\hline \multirow[t]{2}{*}{25} & $\begin{array}{l}\text { I } \\
2 \\
3\end{array}$ & $\begin{array}{c}28 \cdot 39 \\
29 \cdot 64 \\
\ldots\end{array}$ & $\begin{array}{l}5^{60} \\
560 \\
\cdots\end{array}$ & $\begin{array}{c}27 \cdot 04 \\
\cdots \\
32 \cdot 25\end{array}$ & $\begin{array}{l}55^{1} \\
\ldots \\
55^{2}\end{array}$ & $\begin{array}{c}0.253 \\
\ldots \\
\ldots\end{array}$ & \multirow[t]{2}{*}{$-0.5 c$} \\
\hline & Total & $29 \cdot 02$ & I I 20 & $29 \cdot 65$ & I 103 & $0 \cdot I_{1}$ & \\
\hline \multirow[t]{2}{*}{37} & $\begin{array}{l}\text { I } \\
2 \\
3\end{array}$ & $\begin{array}{l}25 \cdot 39 \\
23 \cdot 25 \\
25 \cdot 19\end{array}$ & $\begin{array}{l}453 \\
400 \\
226\end{array}$ & $\begin{array}{l}27 \cdot 16 \\
28 \cdot 06 \\
\ldots\end{array}$ & $\begin{array}{l}545 \\
556 \\
\ldots\end{array}$ & $\begin{array}{c}0.399 \\
2 \cdot 785 \\
\quad \ldots\end{array}$ & \multirow[t]{2}{*}{$\begin{array}{l}0.6 \% \\
1.6 \%\end{array}$} \\
\hline & Total & $24 \cdot 5^{8}$ & I I I 9 & $27 \cdot 61$ & I IOI & $2 \cdot 65$ & \\
\hline \multirow[t]{2}{*}{$4^{2}$} & $\begin{array}{l}\text { I } \\
2 \\
3 \\
4\end{array}$ & $\begin{array}{c}\ldots \\
15 \cdot 75 \\
\cdots \\
\text { I } 8 \cdot 8 \text { o }\end{array}$ & $\begin{array}{l}\ldots \\
400 \\
\ldots \\
399\end{array}$ & $\begin{array}{l}19 \cdot 10 \\
30 \cdot 95 \\
23 \cdot 40 \\
20 \cdot 06\end{array}$ & $\begin{array}{r}89 \\
42 \\
94 \\
324\end{array}$ & $\begin{array}{c}\ldots \\
6 \cdot 721 \\
\ldots \\
0.183\end{array}$ & \multirow[t]{2}{*}{$\begin{array}{l}2.59 \\
0.43\end{array}$} \\
\hline & Total & I $7 \cdot 27$ & 799 & $2 I \cdot 3 I$ & 549 & $3 \cdot 46$ & \\
\hline \multicolumn{8}{|c|}{ Cross 2} \\
\hline \multirow[t]{2}{*}{25} & $\begin{array}{l}\text { I } \\
2\end{array}$ & $\begin{array}{l}23 \cdot 57 \\
22 \cdot 78\end{array}$ & $\begin{array}{l}5^{60} \\
3^{60}\end{array}$ & $\begin{array}{l}24 \cdot 68 \\
24 \cdot 64\end{array}$ & $\begin{array}{l}55^{1} \\
55^{2}\end{array}$ & $\begin{array}{l}0.187 \\
0.414\end{array}$ & \multirow[t]{2}{*}{$\begin{array}{l}0.43 \\
0.64\end{array}$} \\
\hline & Total & $23 \cdot 26$ & 920 & $24 \cdot 66$ & 1103 & 0.18 & \\
\hline \multirow[t]{2}{*}{37} & $\begin{array}{l}1 \\
2\end{array}$ & $\begin{array}{l}20 \cdot 36 \\
23 \cdot 33\end{array}$ & $\begin{array}{l}560 \\
480\end{array}$ & $\begin{array}{l}25 \cdot 86 \\
22 \cdot 14\end{array}$ & $\begin{array}{l}553 \\
55^{1}\end{array}$ & $\begin{array}{l}4.743 \\
0.012\end{array}$ & \multirow[t]{2}{*}{$\begin{array}{r}2 \cdot 7^{2} \\
-0 \cdot 11\end{array}$} \\
\hline & Total & $21 \cdot 73$ & 1040 & $24 \cdot 00$ & I 104 & $1 \cdot 57$ & \\
\hline
\end{tabular}

largest at $42^{\circ}$. The differences between the recombination fractions for $p a b a-y$ in the selected and unselected samples are significant at $37^{\circ}$ and $42^{\circ}$, but for pro-ad they are large enough to be significant only at $42^{\circ}$. 
(b) In the region $y$-bi, which is on the same chromosome as the selective region but separated from it by the region paba-y, the smallest increase, which is not significant, is observed at $37^{\circ}$, and the increases at $25^{\circ}$ and $42^{\circ}$ are larger and significant.

(c) In the region Acr-w, on a different chromosome from the selective region, the relative increases in the recombination fractions in the selected samples are small, and none of them is significant as calculated on the total data. But if there were no real increase in the incidence of recombination in the selected samples, the difference between selective and non-selective recombination fractions should be positive and negative equally frequently. In this cross, there were five cases in which spores were plated on both selective and nonselective media from the same suspension (table 3). In four the recombination fraction for $A c r-w$ in the selected sample was greater than in the unselected sample. For each plating, we may calculate a value of $\chi^{2}$ for one degree of freedom from the numbers of recombinants and non-recombinants growing on each of the two media, and make an overall test of significance on $n$ such values by summing the values of $\sqrt{\chi^{2}}$ (account being taken of whether the difference is positive or negative); this total is distributed normally with mean zero and variance $n$. The sum of the five values of $\chi$ is $4 \cdot 82$, which, with a standard error of $2 \cdot 24$, has a probability of $0.05^{-0} \cdot 02$ if there is no real increase in the selective recombination fractions. Adding comparable data from cross 2 (see below) the recombination fraction was greater in the selected sample in 7 out of 9 platings (table 3 ), and $x=8 \cdot 50 \pm 3.00, \mathrm{P}$ o.0I-0.00I. There appears to be a real increase in the incidence of recombination in $A c r-w$ in meiotic products with an exchange between $a d$ and paba. We then observe that there is an increase in the magnitude of the effect with increasing temperature; the smallest increase is observed at $25^{\circ}$, and the largest at $42^{\circ}$.

\section{2 (ii). CROSS 2}

\section{ad17 bi1; Acr1 w3 $\times$ pro1 paba1 $y$}

In this cross, the same markers were used as in the first cross, but they were differently distributed between the two parents. In cross I, the most frequent class among the $a d^{+} p a b a^{+}$recombinants is $\mathrm{pro}^{+} \mathrm{bi}^{+}$; in cross 2 it is pro bi. The cross was made at $25^{\circ}$ and $37^{\circ}$. The results are given in table 4. The incidence of crossing-over is less in cross 2 than in cross I, but cross 2 agrees with the first in the following essential respects: (i) the recombination fractions in the unselected samples are greater for all regions (except $y$-bi) at $25^{\circ}$ than at $37^{\circ}$; (ii) there are differences in the relative lengths of the various regions at the two temperatures similar to those shown in fig. 3 , and (iii) the relative increase in the recombination fractions in the selected as compared with the unselected samples is greater at $37^{\circ}$ than at $25^{\circ}$ for pro-ad, paba-y and Acr-w, but greater at $25^{\circ}$ than at $37^{\circ}$ for $y$-bi. 
The first point to be noticed in these results is that the selected samples, comprising cross-overs between ad and paba, show a higher incidence of recombination than the corresponding unselected samples in all regions. Next, temperature affects the magnitude of the difference between recombination fractions in the two samples, and the effect of temperature is not the same for all regions.

The increased recombination fractions in selected samples for pro-ad and paba-y, adjacent to the selective region, were expected,

TABLE 4

Results of Cross 2 :

$$
\frac{+a d_{\mathrm{I}}++b i_{\mathrm{I}}}{p r o \mathrm{I}+p a b a \mathrm{I} y+} \frac{A c r \mathrm{I} w_{3}}{++}
$$

\begin{tabular}{|c|c|c|c|c|c|c|}
\hline & \multicolumn{3}{|c|}{$25^{\circ}$} & \multicolumn{3}{|c|}{$37^{\circ}$} \\
\hline & $\mathcal{N}$ & $S$ & $R I$ & $\mathcal{N}$ & $S$ & $R I$ \\
\hline \multicolumn{7}{|l|}{ Chromosome I } \\
\hline proI-ad ${ }_{\mathrm{I}} 7$ & го 76 & I $2 \cdot 15$ & I3 & $7 \cdot 12$ & $9 \cdot 06$ & 27 \\
\hline $\begin{array}{l}a d \mathrm{I} 7-p a b a \mathrm{I} \\
p a b a \mathrm{I}-y\end{array}$ & $\begin{array}{r}0.43 \\
22 \cdot 34\end{array}$ & $\begin{array}{c}\text { selected } \\
32 \cdot 2 I\end{array}$ & $\ldots$ & $\begin{array}{r}0.29 \\
4.57\end{array}$ & $\begin{array}{l}\text { selected } \\
23.66\end{array}$ & $\cdots$ \\
\hline$y-b i_{\mathrm{I}}$ & $\begin{array}{r}2.34 \\
4.12\end{array}$ & $\begin{array}{r}33.73 \\
8 \cdot 73\end{array}$ & $\begin{array}{l}49 \\
112^{*}\end{array}$ & $4 \cdot 16$ & $5 \cdot 18$ & 25 \\
\hline $\begin{array}{c}\text { Chromosome II } \\
\text { Acri-w3 }\end{array}$ & $23 \cdot 26$ & $24 \cdot 66$ & 6 & $2 \mathrm{I} \cdot 73$ & $24 \cdot 00$ & Io \\
\hline \multicolumn{7}{|l|}{ No. of colonies } \\
\hline Total & 920 & I 103 & & 1040 & I IO4 & \\
\hline$w^{+}$ & $4^{6 I}$ & 527 & & 553 & 579 & \\
\hline
\end{tabular}

$\mathcal{N}=$ recombination fraction (per cent.) in unselected samples.

$S=$ recombination fraction (per cent.) in selected samples.

$R I=\frac{S-\mathcal{N}}{\mathcal{N}} \times$ гоo.

* Difference between $S$ and $\mathcal{N}$ significant at 5 per cent. level.

following the work of Pritchard (1955) and Calef (1957), and may be attributed to the clustering of exchanges in short segments of a chromosome. The smallest relative increases (RI in table I) for these regions are at $25^{\circ}$ and the largest at $42^{\circ}$. This may be related to the decreasing incidence of crossing-over in the selective region (as for the whole segment pro-bi: fig. 2) as temperature increases. Pairing and crossing-over in the selective region occur only in a proportion of cells of the whole population, the products of which are found in the selected sample; the smaller this proportion the greater will be the difference between the selected sample and the unselected sample (representing the whole population) in the amount of detectable crossing-over in the short paired segments centred on the selective region. 
Pritchard (1960), studying three very short regions of total map length less than I unit, showed that intense negative interference is highly localised. But in a region far removed from his selective region, he consistently observed small increases in the recombination fractions in the selected as compared with the unselected samples. The results in the present crosses for the region Acr-w, on a different chromosome from the selective region, are comparable. Here the increases, though smaller than for the adjacent regions pro-ad and paba-y, are probably real. This implies a positive correlation between exchanges in the regions ad-paba in chromosome I and Acr-w in chromosome II, which may be a reflexion of a non-random distribution of crossing-over throughout the nucleus. This generalised negative interference is different from and is superimposed on the localised effect. In these heterogeneous populations, the rare cross-overs are more likely to be found in the products of cells with a high incidence of crossing-over in all regions.

The smallest relative increase for Acr-w is at $25^{\circ}$ and the largest at $42^{\circ}$. Thus the strength of this interchromosomal correlation increases as temperature increases and as the incidence of crossing-over decreases. A sample in which there is a positive correlation between exchanges in different chromosomes may differ from an uncorrelated one either in having a less even distribution of crossing-over between cells or in having a more even distribution within cells (Elliott, 1958). In the present genetical data, these alternatives cannot be distinguished, and the basis of the change in correlation with temperature cannot be defined.

The effect of temperature on the relative increase for the region $y-b i$, on the same chromosome as the selective region but not adjacent to it, is different from that for the other regions. The relative increase ( $\mathrm{RI}$ in tables $\mathrm{I}$ and 4 ) is smallest at $37^{\circ}$; and the increases at $25^{\circ}$ and $42^{\circ}$ are very considerable, being actually greater than for the adjacent regions (pro-ad and paba-y) at these temperatures. Generalised non-randomness in the distribution of crossing-over throughout the nucleus would therefore appear inadequate to account for the increases in recombination in selected samples for this region. That the relative increase can be greater in a non-adjacent than in an adjacent region cannot be explained either by Calef's (1957) hypothesis that the increase in non-adjacent regions is due to the inclusion in the selected sample of the products of a small proportion of cells in which the effectively paired segment was so long as to bridge the adjacent region.

The results for $y$-bi could however be due in part to differences between temperatures in the way exchanges are distributed along the one chromosome (i.e. the distribution of the short effectively paired segments), in particular among the doubles and multiples. For there to be any increase in the incidence of recombination in the selected samples, the distribution of exchanges among the various regions must be non-random, i.e. there must be more cells with double and 
multiple exchanges and more with no exchange than expected. The unselected samples contained too few doubles to provide any meaningful data on the spacing of exchanges in double cross-overs at the different temperatures. But if the two exchanges of a double were further apart at $25^{\circ}$ and $42^{\circ}$ than at $37^{\circ}$, and since a proportion of the exchanges in the selective region would be the proximal ones of doubles, the relative increase for $y$ - $b i$ would be greater at the two former temperatures than at the latter.

TABLE 5

Cross 3 :

$$
\frac{r i b o \mathrm{I}+a d \mathrm{I}_{4}+p a b a \mathrm{I} y+}{+a n \mathrm{I}+\text { proI }++b i \mathrm{I}} \underset{\frac{\text { Acr }}{+}}{+} \frac{\text { phen } 2}{+} \frac{\text { meth } \mathrm{I}+}{+ \text { pyro } 4}
$$

Recombination fractions (per cent.) observed in samples of eight interchromosomal recombinants. I 20 colonies were scored in each sample

\begin{tabular}{|c|c|c|c|c|c|c|c|c|c|c|}
\hline $\begin{array}{l}\text { Selective } \\
\text { markers }\end{array}$ & $\begin{array}{l}\text { PYRO } \\
\text { PHEN }\end{array}$ & $\begin{array}{c}\text { Acr } \\
\text { PYRO }\end{array}$ & $\underset{A \mathcal{N}}{M E T H}$ & $\mid \begin{array}{c}M E T H \\
P R O\end{array}$ & $\begin{array}{c}M E T H \\
B I\end{array}$ & $\begin{array}{l}P Y R O \\
R I B O\end{array}$ & $\begin{array}{c}\text { PrRO } \\
A D\end{array}$ & $\begin{array}{l}\text { PrRO } \\
\text { PABA }\end{array}$ & $\begin{array}{c}\text { Hetero- } \\
\text { geneity } \\
\chi^{2}[\tau]\end{array}$ & $\begin{array}{l}\text { Pooled } \\
\text { value }\end{array}$ \\
\hline ribo-an & $19 \cdot 2$ & $18 \cdot 3$ & $27 \cdot 5$ & $18 \cdot 3$ & 23.3 & $15 \cdot 8$ & $14 \cdot 2$ & $16 \cdot 7$ & $8 \cdot 17$ & $19^{\circ}$ \\
\hline an-ad & $6 \cdot 7$ & II $\cdot 7$ & $6 \cdot 7$ & $5^{\circ} 0$ & 2.5 & $6 \cdot 7$ & $9 \cdot 2$ & $2 \cdot 5$ & $12 \cdot 84$ & $\begin{array}{r} \pm 1.27 \\
6.35\end{array}$ \\
\hline ad-pro & $19 \cdot 2$ & $25 \cdot 8$ & $31 \cdot 7$ & $32 \cdot 5$ & $15^{\circ} \mathrm{O}$ & $25 \cdot 8$ & $30 \cdot 0$ & $22 \cdot 5$ & $12 \cdot 64$ & $25 \cdot 3^{1}$ \\
\hline pro-paba & $8 \cdot 3$ & $5 \cdot 8$ & $7 \cdot 5$ & $8 \cdot 3$ & $4 \cdot 2$ & $4^{\cdot 2}$ & $10 \cdot 0$ & $6 \cdot 7$ & $5 \cdot 27$ & $\begin{array}{r}1.88 \\
6.88\end{array}$ \\
\hline$p a b a-y$ & $8 \cdot 3$ & I 3.3 & 12.5 & $15 \cdot 8$ & 13.3 & I 3.3 & I I $\cdot 7$ & I $5 \cdot 8$ & $3 \cdot 70$ & 13.02 \\
\hline$y-b i$ & 0.0 & $5 \cdot 0$ & $4 \cdot 2$ & $4^{\cdot 2}$ & I.7 & $2 \cdot 5$ & $2 \cdot 5$ & $4^{\cdot 2}$ & $\ldots$ & $\begin{array}{r}3.02 \\
+0.55\end{array}$ \\
\hline $\begin{array}{l}\text { Total map } \\
\text { length }\end{array}$ & $61 \cdot 7$ & $79^{\circ} 9$ & $90^{\circ} \cdot \mathrm{I}$ & $84 \cdot I$ & $60 \cdot 0$ & $68 \cdot 3$ & $77 \cdot 6$ & $68 \cdot 4$ & I 3.33 & $73 \cdot 75$ \\
\hline
\end{tabular}

\section{CROSS 3}

ribo1 ad14 paba1 y ; phen2; meth1 $x$ an1 pro1 bi1; Acr1; pyro4

In selected samples of cross-overs between closely linked markers, the incidence of recombination in other regions is higher than in unselected samples of the same meiotic products. In cross 3 the incidence of recombination in selected samples of cross-overs between loosely linked markers was studied. The loosely linked markers were distributed over most of the known length of chromosome I; there were also markers on three other chromosomes (Käfer, 1958). The cross was made at $37^{\circ}$. From a suspension of ascospores from some I 3 perithecia, platings were made on eight different media to obtain recombinants between various markers on independent chromosomes (interchromosomal recombinants) (table 5), and platings were made on nine media to obtain recombinants between markers on chromosome 
I (intrachromosomal recombinants) (table 6). A second suspension was used to increase the sample size for several recombinants. The samples of inter- and intrachromosomal recombinants correspond to unselected and selected samples respectively.

For each region, the recombination fractions in the various unselected samples (i.e. in the samples of different interchromosomal recombinants) agree fairly well, and the total map lengths are also homogeneous (table 5).

TABLE 6

Cross 3:

$\frac{r i b o \mathrm{I}+a d \mathrm{I} 4+\text { paba1 } y+}{+a n \mathrm{I}+\text { pro } \mathrm{I}++b i \mathrm{I}} \frac{+}{A c r \mathrm{I}} \frac{\text { phen } 2}{+} \frac{\text { meth } \mathrm{I}+}{+ \text { pyro } 4}$

Recombination fractions (per cent.) observed in samples of nine intrachromosomal recombinants. I 20 colonies were scored in each sample, except for $Y B I$ where only 33 were recovered

\begin{tabular}{|c|c|c|c|c|c|c|c|c|c|c|c|}
\hline $\begin{array}{c}\text { Selective } \\
\text { markers } \\
x\end{array}$ & $\begin{array}{c}r \\
B I \\
\\
3 \cdot 0\end{array}$ & \begin{tabular}{c|}
$A \mathcal{N}$ \\
$A D$ \\
$6 \cdot 4$
\end{tabular} & $\begin{array}{c}P R O \\
P A B A \\
6 \cdot 9\end{array}$ & $\begin{array}{c}P A B A \\
y \\
\text { I } 3 \cdot 0\end{array}$ & $\begin{array}{c}P A B A \\
B I \\
16 \cdot 0\end{array}$ & $\begin{array}{c}R I B O \\
A \mathcal{N} \\
19 \cdot 2\end{array}$ & $\begin{array}{c}A D \\
P R O \\
\\
25 \cdot 3\end{array}$ & $\begin{array}{c}A D \\
B I \\
48 \cdot 2\end{array}$ & $\begin{array}{l}\text { RIBO } \\
P R O \\
50 \cdot 9\end{array}$ & $\begin{array}{c}\text { Hetero- } \\
\text { geneity } \\
\chi^{2} \text { d.f. }\end{array}$ & $\begin{array}{c}\text { Pooled } \\
\text { value }\end{array}$ \\
\hline ribo-an & $21 \cdot 2$ & $18 \cdot 3$ & $20 \cdot 0$ & $2 \mathrm{I} \cdot 7$ & $20 \cdot 8$ & $\ldots$ & $20 \cdot 0$ & $21 \cdot 7$ & $\ldots$ & $0.48 \quad 6$ & $\begin{array}{r}20.45 \\
\pm \mathrm{I} \cdot 47\end{array}$ \\
\hline$a n$-ad & $12 \cdot \mathrm{I}$ & $\ldots$ & II $\cdot 7$ & $9 \cdot 2$ & 150 & 13.3 & $7 \cdot 5$ & $9^{\cdot 2}$ & $\ldots$ & $4 \cdot 28 \quad 5$ & $\begin{array}{r}11 \cdot 02 \\
\pm 1 \cdot 14\end{array}$ \\
\hline ad-pro & $3^{6 \cdot 4}$ & $3^{2 \cdot 5}$ & $4^{1 \cdot 7}$ & $30 \cdot 8$ & $3^{1} \cdot 7$ & $30 \cdot 0$ & $\cdots$ & $\cdots$ & $\cdots$ & $7 \cdot 37 \quad 5$ & $\begin{array}{r}33.18 \\
\pm 1.87\end{array}$ \\
\hline pro-paba & $9 \cdot \mathbf{I}$ & $12 \cdot 5$ & $\ldots$ & $11 \cdot 7$ & 12.5 & $10 \cdot 0$ & $6 \cdot 7$ & $\ldots$ & $\mathrm{II} \cdot 7$ & $2 \cdot 7^{2} \quad 5$ & $\begin{array}{r}10 \cdot 7^{6} \\
+1.13\end{array}$ \\
\hline$p a b a-y$ & $27 \cdot 3$ & $16 \cdot 7$ & $20 \cdot 0$ & $\ldots$ & $\ldots$ & $10 \cdot 0$ & $18 \cdot 3$ & $\ldots$ & 15.8 & $6 \cdot 45 \quad 5$ & $\begin{array}{r}16 \cdot 75 \\
\pm 1.48\end{array}$ \\
\hline$y-b i$ & $\ldots$ & $3 \cdot 3$ & $4^{2}$ & 5.0 & $\ldots$ & $3 \cdot 3$ & 0.8 & $\ldots$ & 0.0 & $\cdots$ & $\begin{array}{r}2 \cdot 7^{8} \\
\pm 0.61\end{array}$ \\
\hline $\begin{array}{c}y \\
y-(a-x)\end{array}$ & $\begin{array}{r}106 \cdot \mathrm{I} \\
35 \cdot 3\end{array}$ & $\begin{array}{l}83.3 \\
15.9\end{array}$ & $\begin{array}{l}97 \cdot 6 \\
30 \cdot 7\end{array}$ & $\begin{array}{l}78 \cdot 4 \\
17 \cdot 6\end{array}$ & $\begin{array}{l}80 \cdot 0 \\
22 \cdot 2\end{array}$ & $\begin{array}{l}66 \cdot 6 \\
12 \cdot 0\end{array}$ & $\begin{array}{r}53 \cdot 3 \\
4 \cdot 8\end{array}$ & $\begin{array}{r}30 \cdot 9 \\
5 \cdot 3\end{array}$ & $\begin{array}{r}27.5 \\
4.6\end{array}$ & & \\
\hline
\end{tabular}

$x=$ distance between selective markers (from table 5).

$y=$ sum of recombination fractions for intervals outside selective markers.

$a=$ total map length (from table 5 ) $=73.8$ units.

In the various selected samples (i.e. in the samples of different intrachromosomal recombinants) (table 6), the length of the map outside the selective region depends on the length of the selective region. If the selected and unselected samples do not differ in the incidence of recombination, we expect the map length, $y$, of the chromosome outside the selective region in the selected sample to be the same as the total map length in unselected samples, $a$, less the length of the selective region, $x$; i.e. we expect $y=a-x$. In fact, the map length in selected samples is greater than this, i.e. $y>a-x$. Further, the shorter the selective region, the greater is the increase in the incidence of recombination in the selected sample, i.e. the quantity $y-(a-x)$ increases as $x$ decreases (table 6 and fig. 4). The regression coefficient calculated from the values of $y$ and $x$ in table 6 
is $-1 \cdot 5 \mathrm{I} \pm 0 \cdot \mathrm{I}_{4}$, which is significantly different from the expected value of $-\mathrm{I}\left(t_{[7]}=3.53, \mathrm{P} 0.02-0.01\right)$.

This relation is evident only when we add together the lengths of the various regions. The lengths of each region in the various selected samples are homogeneous (table 6); indeed the agreement between them is rather better than in the different unselected samples!

Taking all the selected samples together, the pooled recombination fraction for each region is higher than the pooled value in the unselected samples, except for the distal regions ribo-an and $y$-bi. The

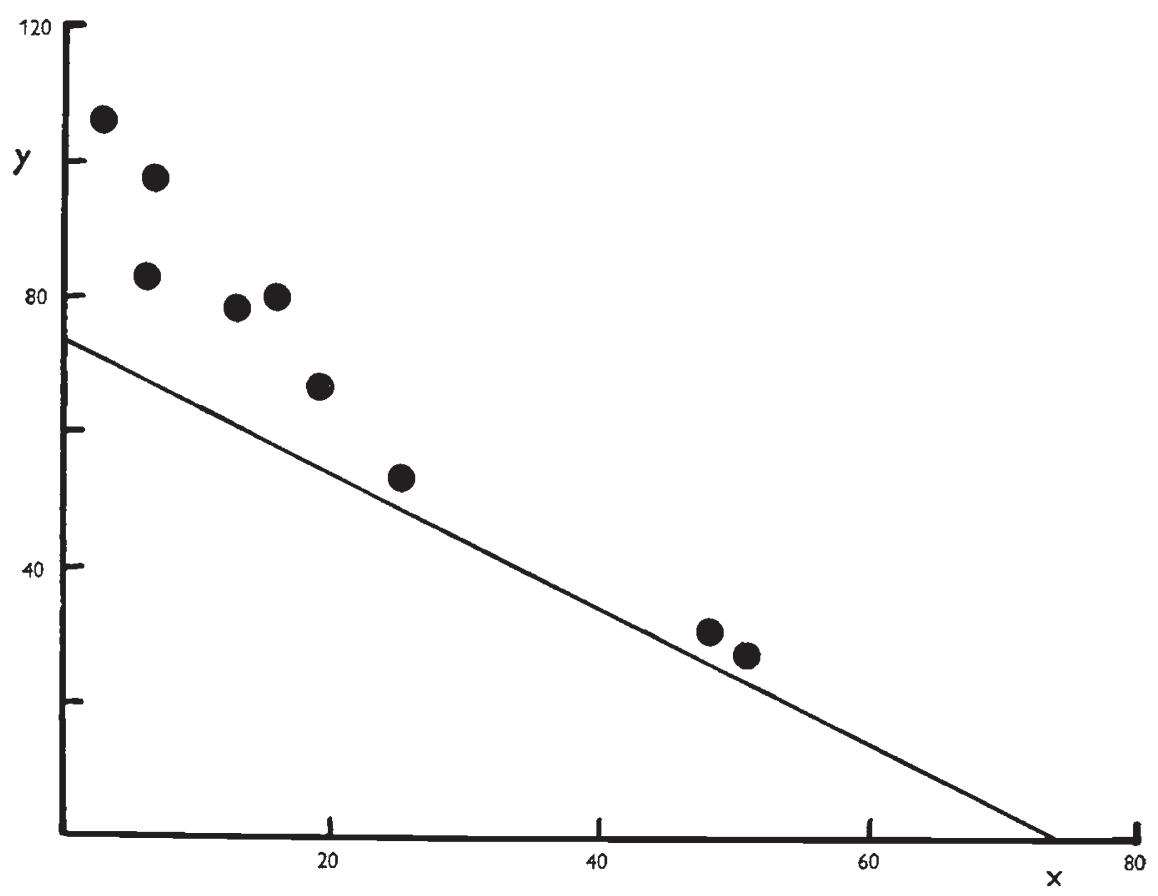

Fig. 4.-Cross 3. The relation between the length of the selective region $(x)$ and the length in selected samples of the map outside the selective region $(y)$. The straight line represents the equation $y=a-x$, where $a=$ total map length in unselected samples $=73 \cdot 8$ units.

greatest relative increases are for the regions an-ad and pro-paba, adjacent to the region ad-pro which includes the centromere. The increased recombination observed in selected samples of cross-overs is not therefore a peculiarity of very rare cross-overs.

The relation between the length of the selective region and the map length outside it in selected samples suggests we have a heterogeneous population in which the rarer cross-overs are more likely to be found in the products of cells with a high incidence of crossingover and the less rare cross-overs in the products of cells with a less high incidence. The incidence of recombination observed in a selected sample of a rare cross-over is therefore greater than in a sample of a less rare cross-over. 


\section{SUMMARY}

A cross was made at three temperatures: $25^{\circ}, 37^{\circ}$ and $42^{\circ}$. For each temperature the incidence of recombination was measured in two samples taken from the same suspension of ascospores (products of meiosis): (i) an "unselected sample" or random sample of the spores, (ii) a "selected sample" of spores showing recombination in a short segment (" selective region ") less than one unit long. The regions measured were two adjacent to the selective region, a further region on the same chromosome, and one on a different chromosome.

In the unselected samples, the recombination fractions for all regions decrease as temperature increases.

In the selected samples, the recombination fractions were greater than in the corresponding unselected samples for all regions. For the regions adjacent to the selective region, the smallest difference between the recombination fractions in the two samples, relative to the length of the regions in unselected samples, was at $25^{\circ}$ and the largest at $42^{\circ}$. For the region on a different chromosome from the selective region, the relative increases in recombination fraction in the selected sample were smaller than for the adjacent regions, but there were real increases; the smallest was at $25^{\circ}$ and the largest at $42^{\circ}$. On the other hand, for the region on the same chromosome as the selective region but not adjacent to it, large differences between the recombination fractions in the two samples were observed at $25^{\circ}$ and $42^{\circ}$, but only a small difference at $37^{\circ}$.

The results are interpreted as due to:

(a) A non-random distribution of exchanges within short " effectively paired" segments.

(b) A weak positive correlation between exchanges throughout the nucleus. The deviation from a random distribution increases with increasing temperature.

(c) Non-random distribution of exchanges among long segments of one chromosome, the distribution of exchanges in double cross-overs being different at different temperatures.

In another cross, the incidence of recombination in selected samples of cross-overs between loosely linked markers was likewise greater than in unselected samples. The difference in map length between the two samples was inversely related to the length of the selective region.

Acknowledgments. - I wish to thank Professor G. Pontecorvo, F.R.s., for his suggestions and criticisms throughout the course of this investigation. The work was supported by a grant from the Nuffield Foundation.

\section{REFERENCES}

CALEF, E. 1957. Effect on linkage maps of selection of cross-overs between closely linked markers. Heredity, II, 256-279.

CHASE, M., AND DOERMANN, A. H. I958. High negative interference over short segments of the genetic structure of bacteriophage $\mathrm{T}_{4}$. Genetics, 43, 332-353. 
ELLIOTT, G. G. 1958. Environmental effects on the distribution of chiasmata among nuclei and bivalents and correlation between bivalents. Heredity, 12, 429-439.

KÄFER, E. 1958. An 8-chromosome map of Aspergillus nidulans. Advanc. Genet., 9, I05-145.

PLOUGH, H. H. I9I7. The effect of temperature on crossing over in Drosophila. 7. $\exp$. Zool., 24, I47-209.

Plovgh, H. H. I92I. Further studies on the effect of temperature on crossing over. F. exp. Zool., 32, 187-202.

PRITCHARD, R. H. I954. Ascospores with diploid nuclei in Asperyillus nidulans. P. Int. Gen. C. (9), I I I 7 .

PRITCHARD, R. H. I955. The linear arrangement of a series of alleles of Aspergillus nidulans. Heredity, 9, 343-37 I.

PRITCHARD, R. H. I96o. Localised negative interference and its bearing on models of gene recombination. Genetical Research, $1, \mathrm{I}-24$.

STERn, C. 1926. An effect of temperature and age on crossing over in the first chromosome of Drosophila melanogaster. P.N.A.S., 12, 530-532.

STREISINGER, G., AND FRANKLIN, N. c. I956. Mutation and recombination at the host range genetic region of phage T2. Cold Spring Harbor Symp. Quant. Biol., 2I, IO3-I I I.

StURTEVAnt, A. H. I955. Evaluation of recombination theory. F. cell. comp. Physiol., 45, suppl. 2, 237-24I. 